\title{
Nano-Grid[n]arenes: A Diverse Platform of Covalently Hierarchical Meta-molecules
}

\author{
Linghai XIE* \\ Center for Molecular Systems \& Organic Devices, Nanjing University of Posts \& Telecommunications, China
}

Received: 眥 February 06, 2018; Published: 酑 February 17, 2018

*Corresponding author: Linghai XIE, Center for Molecular Systems \& Organic Devices (CMSOD), Institute of Advanced Materials (IAM), Nanjing University of Posts \& Telecommunications, 9 Wenyuan Road, Nanjing, 210023, China, Tel: 861875187 6505;

Email: iamlhxie@njupt.edu.cn

\section{Editorial}

In the background of the era of consciousness (EOC) from carbon to robot, we proposed an alternative way via the nanoarchitectures to challenge suspended issues from plastic electronics. Covalent meta-molecules with the features of structural diversity, hierarchy and cross-scale have absolute advantages to decode the universe law of matter and to explore the advanced materials. In the past decade, we focus on a versatile $\mathrm{C}(\mathrm{sp} 3)-\mathrm{C}(\mathrm{sp} 2)$ reaction of fluorenol's Frediel-Crafts protocol (FOH's FCP) [1] as a tool of molecular installing technology, associated with the Pd-catalyzed (sp2)- C (sp2) coupling reaction such as Suzuki cross-coupling reaction. A series of the complex diarylfluorenes (CDAFs), have been synthesized, including small molecules, polymers, as well as covalent nanostructures via the $A_{n}+B_{n}$ and/ or $A_{n} B_{n}$ modes where A represents for fluorenol and $B$ stands for benzeniod substrates [2-8]. Recently, we discovered nano-gridarenes that is a huge family of organic unit nanogrids [9], multigrids [10] as well as polygrids [11] after the exploration of fluorene-based nanosynthesis [12]. Grid polymers serve as the advanced soluble nanopolymers with potential application of light-emitting diodes, lasers, solar cells and memory [13]. In perspective, in the framework of systematically cross-scale and hierarchical chemistry, various meta-structures will be designed and fabricated from the range of zero-dimensional nanomolecules, one-dimensional nanopolymers via strong nano linkages, two-dimensional covalent organic frameworks, and 3D nano-architectures as well as fractal meta-structures via the fluorenol's nanosynthons, offering a series of state-of-the-art models and advanced materials.

\section{References}

1. Xie LH, Hou XY, Hua YR, Tang C, Liu F, et al. (2006) Facile synthesis of complicated 9,9-diarylfluorenes based on BF3 center dot Et2O-mediated Friedel-Crafts reaction. Organic Letters 8(17): 3701-3704.

2. Xie LH, Ling QD, Hou XY, Huang W (2008) An effective Friedel-Crafts postfunctionalization of poly(N-vinylcarbazole) to tune carrier trans portation of supramolecular organic semiconductors based on pistacked polymers for nonvolatile flash memory cell. Journal of the Amer ican Chemical Society 130(7): 2120-2121.

3. Hou XY, Li TC, Yin CR, Xu H, Lin J, et al. (2009) Stable hole-transporting molecular glasses based on complicated 9,9-diarylfluorenes (CDAFs). Synthetic Metals 159(11): 1055-1060.

4. Liu F, Liu JQ Liu RR, Hou XY, Xie LH, et al. (2009) Hyperbranched Framework of Interrupted pi-Conjugated Polymers End-Capped with High Carrier-Mobility Moieties for Stable Light-Emitting Materials with Low Driving Voltage. Journal of Polymer Science Part a-Polymer Chemistry 47(23): 6451-6462.

5. Xie LH, Deng XY, Chen L, Chen SF, Liu RR, et al. (2009) A pi-Stacked and Conjugated Hybrid Based on Poly(N-vinylcarbazole) Postfunctionalized with Terfluorene for Stable Deep-Blue Hole-Transporting Materials. Journal of Polymer Science Part a-Polymer Chemistry 47(20): 52215229.

6. Liu ZD, Chang YZ, Ou CJ, Lin JY, Xie LH, et al. (2011) BF3 center dot Et2O-mediated Friedel-Crafts $\mathrm{C}-\mathrm{H}$ bond polymerization to synthesize pi-conjugation-interrupted polymer semiconductors. Polymer Chemistry 2(10): 2179-2182.

7. Yin CR, Ye SH, Zhao J, Yi MD, Xie LH, et al. (2011) Hindrance-Functionalized pi-Stacked Polymer Host Materials of the Cardo-Type Carbazole-Fluorene Hybrid for Solution-Processable Blue Electrophosphorescent Devices. Macromolecules 44(12): 4589-4595.

8. Chang YZ, Shao Q, Bai LY, Ou CJ, Lin JY, et al. (2013) Bottom-up Synthesis of Nanoscale Conjugation-Interrupted Frameworks and Their Electrical Properties. Small 9(19): 3218-3223.

9. Zhang G, Wei Y, Wang J, Liu Y, Xie L, et al. (2017) A robust molecular unit nanogrid servicing as network nodes via molecular installing technology. Materials Chemistry Frontiers 1(3): 455-459.

10. Wang L, Zhang GW, Ou CJ, Xie LH, Lin JY, et al. (2014) Friedel-Crafts Bottom-up Synthesis of Fluorene-Based Soluble Luminescent Organic Nanogrids. Organic Letters 16(6): 1748-1751.

11. Feng QY, Han Yl, Yu MN, Li B, Wei Y, et al. (2017) A robust and soluble nanopolymer based on molecular grid-based nanomonomer. Chinese Journal of Polymer Science 35(1): 87-97.

12. Xie LH, Hou XY, Tang C, Hua YR, Wang RJ, et al. (2006) Novel H-shaped persistent architecture based on a dispiro building block system. Organic Letters 8(7): 1363-1366. 
13. Yu MN, Ou CJ, Liu B, Lin DQ, Liu YY, et al. (2017) Progress in fluorene-based wide-bandgap steric semiconductors. Chinese Journal of Polymer Science 35(2): 155-170.

\section{(C) (i) This work is licensed under Creative}

To Submit Your Article Click Here:

DOI: $10.32474 /$ AOICS.2018.01.000118

\section{AOICS}

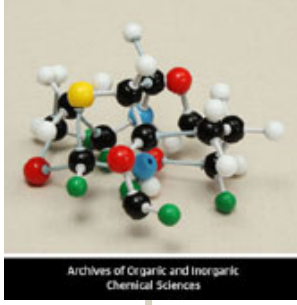

Archives of Organic and Inorganic Chemical Sciences

\section{Assets of Publishing with us}

- Global archiving of articles

- Immediate, unrestricted online access

- Rigorous Peer Review Process

- Authors Retain Copyrights

- Unique DOI for all articles 